\section{The addition of olanzapine to valproate or lithium for acute manic or mixed bipolar episodes reduced manic symptoms}

Tohen M, Chengappa KN, Suppes T, et al. Efficacy of olanzapine in combination with valproate or lithium in the treatment of mania in patients partially nonresponsive to valproate or lithium monotherapy. Arch Gen Psychiatry 2002 Jan;59:62-9.

QUESTION: In patients with acute manic or mixed bipolar episodes, is a combination of olanzapine with valproate or lithium more effective than valproate or lithium alone?
Source of funding: Eli Lilly E Co.

For correspondence: Dr M Tohen, Lilly

Research Laboratories, Eli Lilly \& $\mathrm{Co}$ Indianapolis, IN, USA m.tohen@lilly.com

\section{Design}

6 week randomised \{allocation concealed ${ }^{*} \dagger$, blinded \{patients, clinicians, data collectors, and outcome assessors $\} \dagger^{*}$, placebo controlled trial.

\section{Setting}

33 centres in the US and 5 in Canada.

\section{Patients}

344 patients (mean age 41 y, 52\% women) who had bipolar disorder, manic (48\%) or mixed (52\%) episodes with or without psychotic episodes; had a score $\geqslant 16$ (mean score 22) on the Young Mania Rating Scale (YMRS) at baseline; and had received treatment with a therapeutic blood concentration of lithium (0.6-1.2 $\mathrm{mmol} / \mathrm{l})$ or valproate $(50-125 \mu \mathrm{g} / \mathrm{ml})$ for $\geqslant 2$ weeks before visit 1 . Follow up was $97 \%$.

\section{Intervention}

Patients were allocated (2:1) to olanzapine, $5,10,15$, or $20 \mathrm{mg} /$ day $(\mathrm{n}=229)$ or placebo $(\mathrm{n}=115)$. All patients received valproate or lithium. Adjunctive use of benzodiazepine ( $\leqslant 2 \mathrm{mg} / \mathrm{d}$ of lorazepam equivalents) was permitted for $\leqslant 14$ days cumulatively. Anticholinergic therapy (benztropine mesylate, $\leqslant 2 \mathrm{mg} / \mathrm{d}$ ) could be used for extrapyramidal symptoms but not for prophylaxis.

\section{Main outcome measures}

Severity of manic symptoms (YMRS score), clinical response (improvement of $\geqslant 50 \%$ in YMRS score), and adverse events.

\section{Main results}

Analysis was by intention to treat. Patients in the olanzapine combination group had a greater mean decrease in YMRS score than patients in the control group (table). More patients in the olanzapine combination group than in the control group had a clinical response. Olanzapine combination therapy led to increased weight gain, somnolence, tremor, dry mouth, and speech disorder (table). The groups did not differ for dropouts (table).

\section{Conclusion}

In patients with acute manic or mixed bipolar episodes, the addition of olanzapine to valproate or lithium reduced manic symptoms but increased some adverse events.

*See glossary.

$\dagger$ Information provided by author.
Olanzapine v placebo in addition to valproate or lithium for manic or mixed episodes

\begin{tabular}{|c|c|c|c|c|}
\hline Outcomes at 6 weeks & Olanzapine & Placebo & \multicolumn{2}{|c|}{ Mean difference $(95 \% \mathrm{Cl})$} \\
\hline \multirow[t]{2}{*}{$\begin{array}{l}\text { Mean decrease from } \\
\text { baseline YMRS score }\end{array}$} & 13.1 & 9.1 & $4.0(2.0$ to 6.0$)$ & \\
\hline & & & RBI $(95 \% \mathrm{Cl})$ & NNT (Cl) \\
\hline \multirow[t]{2}{*}{$\begin{array}{l}\geqslant 50 \% \text { improvement on } \\
\text { YMRS }\end{array}$} & $68 \%$ & $45 \%$ & $51 \%$ (23 to 92$)$ & 5 (3 to 9$)$ \\
\hline & & & RRI (CI) & NNH (Cl) \\
\hline Weight gain & $26 \%$ & $7.0 \%$ & $277 \%$ (92 to 658$)$ & $6(4$ to 9$)$ \\
\hline Somnolence & $52 \%$ & $27 \%$ & $91 \%$ (40 to 168$)$ & 5 (3 to 8$)$ \\
\hline Dry mouth & $32 \%$ & $7.8 \%$ & $307 \%(118$ to 684$)$ & 5 (4 to 7$)$ \\
\hline Tremor & $23 \%$ & $13 \%$ & $77 \%(6.6$ to 202$)$ & 10 (6 to 80$)$ \\
\hline Speech disorder & $6.6 \%$ & $0.87 \%$ & $653 \%$ (31 to 4348$)$ & 18 (11 to 75$)$ \\
\hline Dropouts & $30 \%$ & $29 \%$ & $5.0 \%(-25$ to 50$)$ & Not significant \\
\hline
\end{tabular}

YYMRS=Young Mania Rating Scale. Other abbreviations defined in glossary; mean difference, RBI, NNT, RRI, $\mathrm{NNH}$, and $\mathrm{Cl}$ calculated from data in article.

\section{COMMENTARY}

Tohen et al have shown that olanzapine is an effective treatment for mania. Based on the effect size of 0.47 , the primary measure of manic symptom reduction indicated that $68 \%$ ( $95 \%$ CI $59 \%$ to $76 \%$ ) of patients receiving placebo and lithium or valproate improved less than the average patient receiving olanzapine and lithium or valproate. Patients with mixed and pure mania responded similarly to olanzapine augmentation, but the advantage of olanzapine was not statistically significant in patients with pure mania. It is unclear whether olanzapine augmentation should therefore be reserved for mixed episodes or whether the benefit in pure mania is also clinically important and this analysis merely failed to identify this benefit because of low statistical power. Other antipsychotics have been shown to be effective for acute mania and are used commonly. ${ }^{1}$ As such, the next logical question is which antipsychotic is preferred for acute mania.

Although this was an acute treatment trial, antipsychotic treatment often continues for months. As a result, when selecting a treatment for acute mania, clinicians need to consider its effectiveness, safety, and tolerability during maintenance treatment. These issues evoke the debate between newer and older antipsychotics but in a completely different patient population. Long term use of older agents commonly leads to motor side effects in bipolar patients, although weight gain can be substantial with some newer agents. This may be particularly relevant in bipolar disorder because lithium and valproate also cause weight gain. ${ }^{2}$ In this study, olanzapine was associated with a considerable increase in weight relative to placebo $(3.1 v 0.23 \mathrm{~kg})$. Weight gain would be expected to increase with longer use. Clinicians making decisions about whether to use olanzapine or an alternative antipsychotic need to consider this and the related increased risk for weight related health problems. ${ }^{3}$ Making such decisions is complex and should include the patient because individual values will affect treatment acceptance. The results of the 18 month extension of this trial may be helpful and are expected shortly.

\section{David M Gardner, PharmD Dalhousie University Halifax, Nova Scotia, Canada}

1 Gelenberg AJ, Hopkins HS. Antipsychotics in bipolar disorder. J Clin Psychiatry 1996;57(Suppl 9):49-52.

2 Sachs GS, Guille C. Weight gain associated with use of psychotropic medications. J Clin Psychiatry 1999;60(Suppl 21):16-9.

3 Fontaine KR, Heo M, Harrigan EP, et al. Estimating the consequences of anti-psychotic induced weight gain on health and mortality rate. Psychiatry Res 2001;101:277-88. 